
mestre em planejamento urbano pela $\mathrm{COOPe}-$

UFRJ; ex-diretor financeiro da COHAB-RJ; atualmente é gerante da Carteira de Erradicação da Subabitação e Emergências Sociais do BNH.

\title{
Habitação para população de baixa renda
}

\section{Introdução}

As deficiências na oferta de habitações para a população de baixa renda decorrem, em grande parte, da falta de políticas de desenvolvimento urbano que ordenem o uso e a ocupação do solo nas cidades e conduzam à compatibilização das políticas setoriais de investimentos públicos com a demanda de terras e serviços urbanos gerada pelos diversos segmentos da população.

Em face da escassez de recursos para investimentos em obras e serviços urbanos, principalmente a nivel de governo local, tal demanda tem gerado uma competição pelas áreas urbanizadas disponíveis, resultando no alijamento do mercado habitacional de camadas da população de menor poder aquisitivo, contribuindo para a sua marginalização do processo de desenvolvimento local.

Neste contexto, o poder público tem assumido a responsabilidade pela implementação de programas habitacionais destinados à população de baixa renda, buscando atender a essa demanda social que não encontra solução em termos de mercado.

Tal esforço, porém, nem sempre tem sido bem sucedido na escala e no ritmo que se fazem necessários, agravando o acúmulo de déficits habitacionais e de serviços nas áreas urbanas, sobretudo nas de maior porte, resultando na acomodação da população de baixa renda em assentamentos ilegais e/ou irregulares - seja em loteamentos periféricos, seja nas favelas ou nos mocambos.

Uma vez que os estados e municípios, como agentes do governo federal responsáveis pelo cum- primento das metas da política habitacional, tem conduzido seus programas habitacionais de forma setorial e desvinculada das diretrizes de desenvolvimento urbano de seu território, tornaram-se maiores as dificuldades relativas à obtenção de terrenos e serviços urbanos indispensáveis à complementação da habitação.

Considerando a importância e o peso da função habitação na ocupação e estruturação do espaco urbano, assim como os efeitos de sua produção na economia urbana, compreendem-se as dificuldades que se levantam concernentes a uma política voltada para o aumento da oferta habitacional que não esteja integrada a uma política de desenvolvimento urbano do município.

Não obstante, o problema da habitação para a população de baixa renda não poderá ser resolvido apenas pelo lado da oferta, já que as condições de renda dessa população - em um quadro de pobreza urbana típico de nosso estágio de desenvolvimento - exigiriam, para viabilizar a demanda habitacional, alterações nos padrões de distribuição de renda regional e pessoal, os quais dependem de políticas de governo mais amplas.

Para contornar, na medida do possível, tais dificuldades, o poder público tem procurado alternativas que visem à redução dos custos da produção da habitação e dos serviços urbanos, e também tem aumentado os subsídios diretos e indiretos concedidos aos mutuários do Sistema Financeiro da $\mathrm{Ha}$ bitação (SFH).

Assim, apesar da pressão inflacionária sobre os custos dos insumos da produção da habitação e 
sobre os orçamentos familiares, o governo federal tem financiado, através do BNH, programas alternativos de habitação popular, especialmente voltados para melhorar as condições de vida nos assentamentos de subabitações.

Analisando a evolução da política de créditos adotada pelo $\mathrm{BNH}$ ao longo de seus mais de dezoito anos de funcionamento, é possível perceber que o sistema Financeiro de Habitação tem procurado ajustar os programas habitacionais de natureza social ao quadro de deficiências das áreas urbanas em todo o território nacional, o qual define as condicionantes e possibilidades de incorporação dos novos contingentes populacionais ao meio urbano.

Para acelerar o atendimento das necessidades básicas de habitação e serviços da população de baixa renda, em especial nas cidades de médio e grande porte, capitais e regiões metropolitanas, onde se concentram os mais expressivos contigentes populacionais, o BNH tem ampliado seus financiamentos à aquisição e reserva de terras, à infra-estrutura e outros serviços urbanos essenciais, à produção de lotes urbanizados e à urbanização de aglomerados de subabitações.

Além disso, tem ampliado o apoio técnico, financeiro e institucional aos agentes, a fim de incentivá-los a atuar em programas e debates realizados no âmbito do Conselho Nacional de Desenvolvimento Urbano - CNDU - na expectativa de que iniciativas, a nível de estados e municípios, promovam a integração da questão habitacional aos objetivos do desenvolvimento urbano e regional.

\section{O BNH e a habitação para população de baixa renda}

O exame da evolução do Banco Nacional da Habitação no campo da habitação popular, isto é, habitação para a população de baixa renda, nos dará uma visão dos caminhos percorridos no equacionamento da questão pelo governo federal.

Da leitura da lei no 4380/64, que criou o Sistema Financeiro da Habitação (SFH) e o Banco Nacional de Habitação (BNH), institucionalizando os meios de ação para executar o Plano Nacional da Habitação, infere-se que a estratégia do governo estava voltada então, prioritariamente, para o atendimento habitacional dos segmentos sociais de mais baixa renda.

De fato, já no artigo $1^{\circ}$ da referida lei destacase que "...O governo federal, através do ministro do Planejamento, formulará a política nacional da habitação e do planejamento territorial, coordenando a ação dos órgãos públicos e orientando a iniciativa privada, no sentido de estimular a construção de habitações de interesse social e o financiamento da aquisição da casa própria, especialmente pelas classes de população de menor renda"

Por outro lado, o art. $4^{\circ}$. reza que terão prioridade na aplicação dos recursos ". ... co construção de conjuntos habitacionais destinados à eliminação de favelas, mocambos, e outras aglomerações em condições subumanas de habitação".

Assim, as determinações contidas na lei estão indicando que o BNH tem como meta básica o atendimento de uma clientela de baixa renda e que deve portanto ser considerado como um banco de caráter social.

Embora um dos objetivos do governo federal ao criar o BNH e o SFH fosse apoiar a construção civil como um dos setores de maior potencial de geração de empregos e de absorção de mão-de-obra não qualificada, o caráter social da política habitacional, exigindo investimentos de baixa rentabilidade econômico-financeira e subsídios de longo prazo, não autorizava esperar que a iniciativa privada assumisse diretamente a solução da demanda habitacional.

Desse modo, ao ser formulado o modelo brasileiro de habitação popular, observou-se que a promoção dos programas habitacionais destinados às faixas mais carentes deviam ser coordenados e apoiados pelo poder público, reservando a execução das obras às empresas privadas de construção civil. Seria possível, assim, obter a conjugação dos interesses públicos e privados no equacionamento da questão habitacional.

Convém ressaltar que a capacidade de pagamento da população destinatária sendo insuficiente para cobrir todos os custos envolvidos e sendo indispensável subsidiar os investimentos financiados pelo banco, era necessário aplicar também em programas que garantissem uma rentabilidade de tal monta que compensasse os subsídios internos ao sistema.

Por conseguinte, foi buscando o equilíbrio financeiro do SFH que se abriram outras linhas de crédito para financiar habitações a todas as faixas de renda, atendendo ao mesmo tempo a amplas camadas da população e reduzindo o déficit habitacional.

Também a necessidade de ajudar os estados e municípios na instalação dos equipamentos urbanos indispensáveis à complementação das habitações produzidas, levou o BNH a criar outras linhas de crédito destinadas ao financiamento de infra-estrutura e equipamentos comunitários. Assim, ao longo de sua existência o BNH empenhou-se em oferecer recursos de empréstimo que viabilizassem o desenvolvimento da política habitacional, sempre 
dentro do princípio de manter os subsídios internos ao sistema, entre agentes e programas de maior capacidade econômica e rentabilidade e agentes e programas de natureza social.

O exame da atuação do BNH no campo da habitação popular pode ser analisado através de diferentes períodos. O primeiro período, que pode ser entendido como de implantação e consolidação do SFH - de 1964 a 1972 - caracterizou-se na área da habitação de baixa renda por um esforço em aumentar a oferta de novas unidades habitacionais através das Companhias de Habitação Popular $\mathrm{COHABs}$. Apenas em caráter excepcional poderia ser financiada a construção de equipamentos comunitários ou infra-estrutura, não se admitindo o financiamento da aquisição de terrenos nem a remuneração dos custos administrativos dos agentes.

Só em 1970 o BNH baixou uma resolução estendendo a concessão de empréstimos para a aquisição de terrenos, execução de obras de infraestrutura ou outras obras necessárias à implantação e à integração de conjuntos residenciais na estrutura urbana. Na verdade, essa resolução veio corrigir uma falha existente, uma vez que as prefeituras municipais e as concessionárias de serviços públicos nem sempre podiam responsabilizar-se, diretamente, pela execução de tais equipamentos, resultando em unidades habitacionais sem condições de uso.

Nesse período, o BNH financiou cerca de 250 mil unidades habitacionais, através das $\mathrm{COHABs,}$ destinadas à população de baixa renda. Não obstante, o déficit habitacional nessa faixa de renda continuou crescendo, já que o explosivo crescimento demográfico das áreas urbanas brasileiras deu-se, principalmente, por fluxos de migrantes de baixa renda com escassas possibilidades de inserção no mercado de trabalho urbano e sem alternativas de acesso a uma moradia convencional. Desta forma, o problema da habitação social permanecia sem solução definitiva.

Por outra parte, a experiência até então desenvolvida demonstrou que qualquer programa habitacional destinado aos grupos de menor poder aquisitivo tem que se inscrever, para ser viável e eficaz, em um contexto mais amplo, em que a habitação é requisito essencial e de primeira importância, mas, ainda assim, insuficiente em si mesmo para garantir uma efetiva promoção social das populacões carentes. Tal população, normalmente, apresenta índices muito baixos de educação, formação profissional, saúde etc. , resultando em um contingente de desempregados ou subempregados, com dificuldades de cumprir pontualmente seus compromissos financeiros com a aquisição da casa própria ou mesmo de arcar com a necessária manutenção de sua moradia.
Assim, aos usuários dos conjuntos habitacionais a oferta dos serviços urbanos básicos e a execução simultânea de programas de desenvolvimento comuntário apareceram como componentes indispensáveis ao planejamento habitacional para os grupos de menor renda.

Este diagnóstico foi a base da formulação, em janeiro de 1973, do Plano Nacional da Habitação Popular - PLANHAP. Seu objetivo estratégico era eliminar em um decênio o déficit acumulado e assegurar $\mathrm{o}$ atendimento da demanda adicional de habitações para as famílias urbanas com renda regular entre um e três salários mínimos regionais. Para tanto, no âmbito do PLANHAP, criaram-se vários instrumentos, a saber: o programa FINC de financiamento para urbanização de conjuntos habitacionais, o programa FINEC de financiarmento de equipamentos comunitários, a participação do BNH em programas de desenvolvimento comunitário, programa de assistência técnica às COHABs, financiamento dos custos relacionados a planejamento, fiscalização e administração de conjuntos habitacionais, programa de financiamento ao capital de giro das COHABs, taxas de cobrança e administração de créditos e de apoio comunitário, financiamento de aquisição de terrenos para a construção de núcleos habitacionais.

Em 1975, visando a reduzir as prestações de amortização dos financiamentos habitacionais, decretou-se a concessão de benefício fiscal aos adquirentes de imóveis do SFH, outorgando-Ihes um crédito proporcional ao total de pagamentos efetuados com a amortização do financiamento, no ano base correspondente, dentro de limites máximos e mínimos que procuram beneficiar os mutuários de renda mais baixa.

Cumpre destacar ainda em 1975 o surgimento do Programa de Financiamento de Lotes Urbanizados - PROFILURB - com o qual pretendeu o BNH viabilizar uma solução habitacional para maior contingente populacional que, por situar-se em extratos de renda mais baixa, não podia habilitar-se aos financiamentos concedidos para aquisição de uma unidade pronta.

A criação do PROFILURB assume um caráter especial, já que foi a primeira vez que o sistema reconhecia formalmente as dificuldades de cumprir seus objetivos dentro das limitações econômicas e financeiras que se impunham.

Os fundamentos básicos da concepção do programa incorporaram observações relativas ao processo de ocupação do solo e ao comportamento espontâneo da população de baixa renda, entre as quais destacam-se: a) a grande mobilidade gerada pela instabilidade de emprego; b) o processo de morar das famílias de baixa renda, regido principal- 
mente por fatores de localização e disponibilidade de terras e em função de suas necessidades e expectativas de integração à economia urbana; c) a propriedade da habitação nem sempre corresponde à necessidade mais imediata dessa população, visto que, em alguns casos, famílias com renda suficiente não se interessam por comprar a casa pronta e sim o lote; d) os preços finais das 'habitações acabadas' nem sempre são suportáveis por famílias situadas nos extratos inferiores de renda lo item edificação vem representando cada vez maior parcela nos preços finais das unidades, restringindo assim a tais famílias as possibilidades de acesso à habitação); e) os grandes investimentos necessários à execução de conjuntos habitacionais, em obras a cargo do poder público, nem sempre são compatíveis com suas possibilidades e/ou prioridades, ocasionando elevado custo social - que poderia ser minimizado pelo aproveitamento de áreas ociosas ou inadequadamente utilizadas; f) a redução do déficit habitacional requer soluções alternativas à construção de habitações acabadas.

Na realidade o PROFILURB apresentava-se como uma solução dinâmica em que o morador era incorporado ao processo de produção das habitações e ao equacionamento do seu próprio problema habitacional.

Em complementação ao Programa de Financiamento de Lotes Urbanizados, o BNH instituiu em 1977 o Programa de Financiamento da Aquisição de Materiais de Construção - FICAM - para a construção, melhoria e/ou recuperação de habitações, permitindo à família - que adquiriu um lote urbanizado pela $\mathrm{COHAB}$ ou tem um lote próprio - receber crédito para a compra de materiais a serem utilizados na edificação ou ampliação de sua moradia.

Tal programa veio atender a uma larga faixa do mercado habitacional, principalmente aquela localizada em loteamento periféricos, a qual, apesar de possuir um lote adquirido com seus recursos próprios, não dispunha de meios para construir a moradia.

De 1977 a 1980 nenhum outro programa foi criado já que também esse período correspondeu a um interregno de final e mudanças de governo. Não obstante os resultados alcançados, a saber: construção de mais de 2.000 .000 de unidades no período de 1964/1978, implantação de saneamento básico em mais de dois mil municípios, conscientização da população para o hábito de poupança voluntária e abertura de linhas de financiamento para estado e municípios, a problemática habitacional, especialmente a habitação popular, continuou desafiando as intenções e a imaginação das autoridades responsáveis pelo seu equacionamento.
Muitas são as razões para tal impasse, entre outras: a) a dimensão do déficit habitacional acumulado antes da criação do BNH e do SHF; bl o processo de urbanização brasileiro, concentrado/desequilibrado e desigual, pressionando os recursos públicos em serviços urbanos básicos, disputando a terra disponivel, gerando em face da escassez de recursos, a níveis estadual e local, um déficit não só de habitações mas também de água, transporte, esgoto etc.; c) as desigualdades de renda pessoal e regional e a crescente pobreza urbana inviabilizando os programas habitacionais por incapacidade dos governos locais e de grande percentual da população do país em arcar com os ônus dessa urbanização; d) o aumento acelerado dos custos da construção civil e dos preços de venda da habitação popular que ocorrem a ritmo bem superior ao dos salários, determinando, em conseqüência, que o crescimento da demanda efetiva seja bem inferior ao das necessidades reais; e) a perda de poder aquisitivo real da população impossibilitando que as famílias de fato comprometam seus orçamentos com amortização dos financiamentos nos níveis necessários.

Assim, em 1979, ao formular as diretrizes básicas do Ministério do Interior no campo da habitação, o ministro Mário Andreazza reconheceu que o BNH deveria voltar sua atuação, prioritariamente, para o atendimento das classes de população de menor poder aquisitivo. Salientou ao mesmo tempo que os programas de habitação popular deveriam ser redefinidos no sentido de atingir as famílias com renda de até três salários mínimos regionais. Dentro desse enfoque, reconheceu o governo, ainda, a necessidade de conceder-se um tratamento especial ao problema dos chamados 'aglomerados de subabita-
cões.

Na Exposição de Motivos n. 066 , de 25 de junho de 1979, que propôs a criação do Programa de Erradicação da Subabitação (PROMORAR), o governo federal admitia que a questão da subabitação vinha desafiando a ação dos poderes públicos em diversas regiões do país, visto que, não raras vezes, as soluções aplicadas em grande escala acabaram por criar nova gama de problemas sociais, seja pelos ônus transferidos aos usuários seja pelo seu afastamento para a periferia urbana, onde se encontravam os terrenos com dimensões e preços adequados aos programas habitacionais convencionais.

A criação do PROMORAR veio de fato coroar toda uma evolução do pensamento oficial sobre a questão, como vimos acima, procurando acelerar a extensão dos benefícios do Sistema Financeiro da bana, em especial aquela de até três salários mínimos, ainda não atendida pelos programas em vigor na escala que se fazia necessária. 
Na verdade, o PROMORAR representou um novo enfoque para a problemática da habitação popular, uma vez que suas premissas básicas foram: a) promover a melhoria das condições de vida da população de baixa renda que vive em assentamentos de subabitações, integrando-a física e socialmente às estruturas urbanas; b) essa integração pressupõe a manutenção da população nas áreas onde se localiza, conservando inalteradas as estruturas sociais e as relações de emprego existentes; c) resolver com prioridade os problemas relativos à posse da terra e de provisão dos equipamentos e serviços urbanos, aspectos nos quais a população de baixa renda é totalmente dependente dos poderes públicos; d) recebendo o binômio terra/infra-estrutura, a população de baixa renda, por intermédio de pequenas modificações nos esquemas de financiamento já existentes, tem condições de resolver o seu probema habitacional; e) somente através de uma participação ampla e ativa no programa, a população de baixa renda se fixará nas áreas recuperadas; fi considerando as dimensões do problema e a escassez dos recursos disponíveis, é necessário rever os padrões urbanísticos e de serviços urbanos vigentes, que, no Brasil, freqüentemente são meras cópias de países mais adiantados, adequando-os a nossa realidade de país em desenvolvimento.

Definidas essas premissas básicas, estabeleceram-se as normas operacionais do PROMORAR, através de uma resolução de diretoria do $B N H$, as prioridades do programa, a estrutura administrativa encarregada de sua gestão e a estratégia a ser perseguida em sua implantação.

As condições de financiamento, dados os objetivos sociais do programa, foram excepcionais: juros (2\% para os mutuários finais), prazo de amortização (de 360 meses), antecipação do benefício fiscal permitindo a redução de todas as prestações mensais, estímulo aos pequenos projetos através de uma melhor remuneração aos agentes promotores, taxa de administração do BNH $(1 \%)$, eliminação do Fundo de Compensação de Variação Salarial (até 300 UPC), percentual de financiamento $(100 \%)$, incluindo custos de elaboração de todos os projetos, valor de financiamento máximo a ser transferido às famílias de 300 UPC, hoje equivalente a $\mathrm{Cr}$ \$ 873.279,00 (oitocentos e setenta e três mil, duzendos e setenta e nove cruzeiros) o que viabiliza um comprometimento de renda com os pagamentos mensais de amortização de apenas $10 \%$ de renda familiar para as famílias de um e meio salários mínimos.

As normas operacionais adotadas foram extremamente flexíveis, permitindo, inclusive, e quando necessário, que o BNH atuasse em primeira linha. Tal flexibilidade permite que sejam financiados obras de infra-estrutura, equipamentos comunitários, e tor- na possível a geração de terrenos através de aterro de áreas alagadas, diferentes alternativas habitacionais; permite que se apóie projetos de grande porte nas principais capitais e áres metropolitanas ou pequenos projetos em cidades do interior; que se conceda empréstimos a governos de estados ou municípios através dos mais diversos agentes financeiros, por exemplo.

A estratégia inicial, quando do lançamento do PROMORAR, foi dar prioridade à recuperação dos assentamentos localizados sobre palafitas em áreas alagadas ou inundáveis. Esse tratamento prioritário decorreu dos seguintes fatores: a) tais assentamentos apresentavam os mais baixos níveis de salubridade, segurança e higiene das habitações; b) tais áreas, que foram, via de regra, abandonadas no processo normal de ocupação das cidades litorâneas ou ribeirinhas, hoje, com a expansão acelerada desses núcleos, ocupam posição privilegiada em relação ao mercado de trabalho e de serviços; c) o saneamento e a recuperação dessas áreas através do aterro hidráulico, além de resolver o problema das palafitas, mantendo os favelados em seu local de moradia, permite, pela geração de novos terrenos, abrigar outras famílias de baixa renda, inscritas no Sistema Financeiro de Habitação; d) através de venda de terrenos remanescentes poderão ser ressarcidos os investimentos realizados na recuperação da área, tornando os projetos autofinanciáveis.

$\mathrm{Na}$ realidade, a perspectiva de desenvolver grandes projetos, com impacto sobre as respectivas áreas urbanas, ao mesmo tempo em que se implantava uma ação de cunho social, concorreu muito naturalmente para estimular o entusiasmo das autoridades em todos os níveis de governo. E assim o PROMORAR nasceu sob a inspiração de projetos de grande porte, envolvendo uma multiplicidade de agentes e exigindo investimentos vultosos.

Não obstante, tais projetos demandavam um prazo de maturação bastante longo e implicavam em intervenções muito drásticas no ambiente dos aglomerados selecionados, requerendo dessa forma um trabalho lento de integração e aceitação da comunidade envolvida pela solução proposta.

Assim, com o objetivo de consagrar, junto aos governos estaduais e municipais, a filosofia do PROMORAR e permitir a obtenção a curto prazo de uma experiência diversificada em todo o país, conseguiuse aprovar uma estratégia de, paralelamente, implantar pequenos projetos, oferecendo uma estreita colaboração com aqueles governos estaduais ou municipais sensibilizados pela proposta do Ministério do Interior, através do BNH. Houve, ainda, uma ênfase especial em procurar atuar nas capitais do Nordeste e cidades de porte médio da região, consideradas locais de passagem da grande massa de mi- 
grantes que se dirige às regiões metropolitanas do Rio de Janeiro e São Paulo.

As expectativas foram superadas pela realidade: três anos após sua criação, o PROMORAR já financiou projetos no montante de

Cr\$234.694.202.820,00 (duzentos e trinta e quatro bilhões, seiscentos e noventa e quatro milhões duzentos e dois mil oitocentos e vinte cruzeiros), beneficiando cerca de 212.036 famílias e gerando a produção de 167.883 unidades habitacionais.

A expressividade da atuação do PROMORAR não reside apenas nesses números, mas, também, na extensão territorial que atingiu, na diversidade de agentes engajados, no crescimento de demanda de recursos, na aceitação irrestrita dos governos estaduais, no entusiasmo de vários prefeitos, na colaboração da Pastoral de Favelas no Rio de Janeiro, no entrosamento com a LBA e com o Projeto Rondon, na agilização do processo de transferência de terras de domínio da União, no número de títulos de propriedade já outorgados, no trabalho junto com as associações de moradores, e, mais especialmente, no bem-estar e na alegria manifestada pelas famílias beneficiadas.

A pouca experiência na implantação de projetos de urbanização de favelas, no Brasil e no mundo, na escala e dimensões que o PROMORAR pretende, impõe um trabalho de avaliação permanente, no sentido de permitir o aperfeiçoamento do próprio programa.

A avaliação se faz necessária para medir o grau de satisfação dos usuários e o alcance dos objetivos do programa, e, além disso, para permitir redirecionar prioridades, ajustar procedimentos e identificar pontos de estrangulamento no desenvolvimento do programa.

Carecemos ainda de dados consistentes para poder fazer afirmações válidas sobre uma ou outra experiência, a não ser aquelas conclusões óbvias a que se pode chegar pelo acompanhamento e observações direta da realidade.

No entanto, temos certeza que o alcance pleno dos objetivos do Ministério do Interior com a política de urbanização dos aglomerados de subabitação pressupõe a canalização de recursos adequados, em montantes crescentes, compatíveis com a demanda resultante da mobilização dos governos estaduais e municipais em todo o país, os quais desejam arcar com suas responsabilidades frente às comunidades, mas necessitam de apoio financeiro do governo federal, seja sob a forma de transferência de recursos seja sob a forma de empréstimos.

Nesse sentido, a criação do Fundo de Investimento Social - FINSOCIAL - pelo governo fede- ral veio abrir novas perspectivas para o desenvolvimento do PROMORAR. As possíveis mudanças que poderão gerar as aplicações dos recursos do FINSO$\mathrm{CIAL}$ na área de habitação certamente vão contribuir para viabilizar a extensão dos benefícios do programa a custos sensivelmente menores às mais amplas camadas da população de baixa renda.

Considerando as causas e as características do processo de formação dos aglomerados de subabitações, constatamos que, para evitar-Ihes o crescimento em todo o país, seriam indispensáveis, entre outras, as seguintes medidas: a) alteração do padrão de investimentos de capital - sejam públicos ou privados -, os quais são indutores da concentração espacial do emprego e, portanto, da população em poucas áreas urbanas do país; b) reducão das desigualdades de renda regional e pessoal, geradoras de desequilíbrios no desenvolvimento urbano e regional do país; c) alteração da legislação urbana vigente de controle do uso do solo, a nível de cada município e região metropolitana; d) alteração de legislação fiscal e tributária sobre a propriedade de imóvel urbano, especialmente do imposto predial e territorial urbano (IPTU) de responsabilidade dos governos locais; e) redirecionamento de prioridades das politicas de investimento público em infra-estrutura, equipamentos e serviços urbanos; f) intervenção no mercado de terras urbanas, garantindo estoque de terrenos a preços compatíveis com a habitação de baixa renda; g) execução de um programa maciço de investimentos na producão de unidades habitacionais e respectiva infra-estrutura, a fim de responder à demanda das famílias de baixa renda que chegam às cidades.

A amplitude, abrangência, as implicacões de ordem político-institucionais - já que envolvem diversos níveis de governo - e as repercussões da ordem econômica, inclusive em nível macro na economia nacional, das medidas acima apontadas, evidenciam que ainda vamos conviver algum tempo com os problemas gerados pelo processo de urbanização acelerada que enfrentamos em um contexto de escassez de recursos para investimentos não produtivos.

Assim, enquanto se estudam e se procuram viabilizar, a médio e a longo prazos, as reformas econômicas, sociais e urbanas necessárias à superação da pobreza urbana, cumpre desenvolver estratégias que visem, a curto prazo, melhores condicões de vida para esse imenso contingente da população que procura se incorporar ao meio urbano.

\section{Considerações finais}

Examinadas as alternativas adotadas pelo governo federal, através do BNH, para ampliar o aten- 
dimento da população de baixa renda, reportamonos em seguida às nossas preocupações iniciais.

Em face do quadro urbano brasileiro, que se apresenta atualmente como resultante do processo de desenvolvimento político, social e econômico do país nas últimas décadas, qual a estratégia - ou estratégias - que ajudará a equacionar os problemas da habitação popular?

Uma vez que a capacidade dos estados e municípios de aumentarem a produção de conjuntos habitacionais convencionais estará cada vez mais restrita, poderemos concluir que a estratégia para melhorar as condições habitacionais da população de baixa renda deve basear-se na experiência de urbanização de favelas e loteamentos periféricos desenvolvida através de programas como o PROMORAR, o PROFILURB e o FICAM.

Enumeramos a seguir os seus pontos básicos.

1. Dar prioridade aos investimentos em infraestrutura e outros equipamentos urbanos, bens públicos de consumo coletivo, que não podem, via de regra, ser realizados individual ou isoladamente pelo setor privado.

Visto que os investimentos na construção das unidades habitacionais podem ser mais facilmente enfrentados por iniciativa e esforço próprio da população de baixa renda, a viabilização de investimentos em equipamentos urbanos complementares à habitação - como é o caso dos programas acima mencionados - pode contribuir em muito para atenuar os efeitos do déficit habitacional do país. Além disso, tais investimentos também contribuirão para atenuar os efeitos da crise econômica por que passamos, já que apresentam efeitos redistributivos da renda real mais significativos que os investimentos diretos em produção de habitações.

2. Buscar a otimização dos investimentos públicos a fim de ampliar os benefícios sociais gerados pelo capital aplicado. Tal otimização pode ser alcançada através da integração e coordenação das intervenções planejadas pelo poder público.

Dever-se-á procurar a integração e coordenação das intervenções do setor público, uma vez que economias de escala e de aglomeração podem viabilizar investimentos sociais e reduzir custos, tornando também menor o prazo de maturação dos projetos e antecipando-lhes os benefícios.

A forma mais econômica e eficiente de intervir em qualquer área urbana, especialmente se ocupada, é integrando os investimentos em infra-estrutura, edificações, aquisição de áreas etc. 0 tratamento setorial das carências urbanas tem levado a soluções que exigem investimentos custosos para resolver os problemas. Tentar solucionar o problema de habitação de baixa renda isoladamente acarreta ônus adicionais para as prefeituras e concessionárias, à margem de suas programações de obras, e demandam por isso um grande esforço de negociação a fim de ajustar as prioridades de cada agente. A integração de investimentos exige, porém, elevado grau de coordenação e deve ser perseguida desde o planejamento, a programação e a execução das obras, serviços e atividades necessárias.

A urbanização de aglomerados de subabitações caracteriza-se por projetos integrados da legalização da propriedade da terra, da implantação de infra-estrutura, melhoria das habitações e oferta de serviços sociais, aproveitando essencialmente os investimentos já aplicados na área seja pela própria população seja pelo setor público. Os aspectos legais têm que ser abordados da mesma forma que os aspectos econômicos, sociais e técnicos do aglomerado, para que seja adequadamente urbanizado.

3. Procurar reduzir os custos das obras e serviços a serem implantados. Esta redução deverá ser obtida quer pela adoção de padrões de projeto compatíveis com a situação de escassez em que vive a população urbana, quer pelo ajustamento do ritmo de obras aos fluxos de recursos disponiveis, quer pela gestão eficiente e adequada dos projetos.

Vivemos em uma conjuntura que nos obriga a repensar os padrões de urbanização referentes ao uso e ocupação do solo e aos diversos equipamentos e serviços urbanos exigidos pelas leis, normas e regulamentos impostos pelas autoridades competentes em todos os níveis.

A adoção de soluções alternativas de baixo custo, a adequação tecnológica, o aproveitamento dos investimentos já realizados, contribuirão para a redução dos custos de urbanização, permitindo que se ofereça melhores condições de vida às mais amplas parcelas da população.

Acabaram-se os tempos das obras de grande escala, as soluções difíceis, suntuárias e supérfluas, os projetos-impacto. Os tempos exigem criatividade no uso dos recursos e insumos disponiveis e a aceitação das transformações e adaptações resultantes da crise urbana que atravessamos.

As intervenções urbanas que se devem planejar se situam muito mais na linha da urbanização dos assentamentos existentes do que na construção de novos conjuntos habitacionais para alojar a população carente.

4. A mobilização dos recursos privados é um dos aspectos mais importantes de programas como o PROMORAR, o PROFILURB e o FICAM, onde se entende a habitação como um processo e não um produto acabado. 
A experiência demonstra que existem recursos para investir na satisfação de necessidades consideradas pela população como essenciais à sua sobrevivência no meio urbano, seja sob forma de capacidade de poupança a ser canalizada adequadamente para o alcance dos objetivos prioritários, seja sob forma de mão-de-obra que pode ser acionada nas comunidades empenhadas em resolver seus problemas de moradia.

A mobilização de tais recursos depende do grau de participação da comunidade no projeto, a qual pode oferecer considerável contribuição para a redução dos custos das obras e serviços e para a antecipação dos benefícios pretendidos.

No caso da moradia, a participação pode darse diretamente através de processo de autoconstrução ou de mutirão comunitário ou, indiretamente, nas decisões dos moradores relativas às intervenções planejadas para a sua vizinhança.

Quanto a autoconstrução, a família, ao invés de receber um produto acabado, convencional, padronizado - que pode não responder às suas necessidades ou aspirações - , é orientada no sentido-de ser parte ativa do processo de melhoria ou construção de seu habitat.

Essa convocação para que o usuário divida responsabilidades com o poder público na conformação de seu meio ambiente, nada mais é que a aplicação prática, na área habitacional, da metodo- logia do planejamento participativo, muito estudada, discutida e recomendada pelos técnicos e raramente operacionalizada no contexto brasileiro.

Ao exercitar-se a população de um lado e os técnicos de governo de outro, nas práticas do planejamento participativo, poder-se-á abrir caminho para estender tal experiência à discussão mais ampla em torno de problemas que interessam ao desenvolvimento urbano do município.

O poder público dispõe ainda de vários outros instrumentos adequados para canalizar recursos privados, da população ou do setor empresarial, para enfrentar o problema da habitação de natureza social.

Instrumentos legais, fiscais, tributários e administrativos que induzam o uso e a ocupação do solo de acordo com os objetivos de desenvolvimento urbano do município e que facilitem o acesso e a fixação da população carente em áreas urbanizadas adequadamente localizadas. Através da adoção segura de tais mecanismos de sua competência, os estados e municípios estarão atuando, de forma significativa, para atenuar as conseqüências indesejáveis do crescimento urbano desordenado do país, no âmbito de seus territórios.

Neste sentido, administrar e planejar o seu desenvolvimento urbano é uma das contribuições mais importantes que os governos locais podem oferecer à viabilização da política do governo federal voltada para a habitação popular. 